\title{
The Concept of Cooling System for HTS Winding due to the Power Losses in Superconducting Transformer
}

\author{
G. WojTASIEWICZ* \\ Electrotechnical Institute, M. Pożaryskiego 28, 04-703 Warsaw, Poland
}

\begin{abstract}
The aim of this paper is to present the problems of cooling systems design for superconducting devices on the example of superconductor transformer. The authors have designed superconducting power transformer with primary and secondary windings wound of several parallel YBCO $2 \mathrm{G}$ tapes. The power losses in a superconducting transformer as well as additional losses in a superconducting tapes connected in parallel were described, too. The core of the transformer is placed in a cryostat with a room temperature bore. The proposal of contact cooling system for transformer windings as well as the conditions and parameters for achieving cryogenic work temperature for that winding were presented. The main part of cooling system are two contact cryocoolers working in closed cooling cycle. The conclusion highlights the future perspective of developed cooling method application in $2 \mathrm{G}$ high temperature superconducting transformers.
\end{abstract}

DOI: 10.12693 /APhysPolA.135.14

PACS/topics: 74.90.+n, 84.70.+p, 84.71.-b, 85.25.-j, 85.25.Am, 85.25.Qc

\section{Introduction}

Superconducting devices like a magnetic energy storage (SMES), a superconducting current limiter (SFCL), or a transformer bring new challenges regarding their design and operation $[1,2]$. The design of the superconducting winding and choice of cooling technology are very important from a point of view of the efficiency of the devices.

The most commonly used method of cooling transformer windings made of high temperature superconducting (HTS) tapes is cooling in the bath of liquid nitrogen. It is a simple method and does not require a complicated cryostat. However, due to the permanent loss of liquid nitrogen, it requires an additional system of its continuous refilling. On the other hand, commonly available and more and more efficient (also cheaper in the purchase and maintenance) cooling systems, operate on the basis of mechanical cryocoolers, allow to easily lower the operation temperature and enable the windings to work at a temperature lower than $77 \mathrm{~K}$. These are fully autonomous systems, requiring only the power to operate, so it could be fully automated [3].

\section{Power losses \\ in a superconducting transformer}

Power losses in a superconducting transformer consist of the losses in the superconducting windings, the losses in the iron, and the losses in the cryostat and in the current leads [4]. These losses are divided into load losses and constant losses.

*e-mail: g.wojtasiewicz@iel.waw.pl
Load losses are further divided into:

- losses in the superconducting windings occurring as a result of the flow of $\mathrm{AC}$ current in the superconducting windings - self-field losses; the interaction of external alternate magnetic field - hysteresis losses and eddy-current losses;

- losses in current leads.

Constant losses are further divided into:

- iron losses;

- cryostat losses.

The hysteresis losses are in direct proportion to the thickness of the superconductor layer. The main method to limit them is to make a $2 \mathrm{G}$ superconducting tape with the thinnest possible superconductor layer. If the dimensions of the superconductor perpendicular to the magnetic field are small, we also achieve limitation of hysteresis losses.

The hysteresis losses value also depends on the type and design of the windings and their radial dimensions (thickness). Types of transformer windings include coil windings, in the form of single or double coils, and in the form of layer windings - screw windings.

Because of the thickness of superconducting tapes, the dimensions of superconducting windings (i.e. diameter and thickness of the windings) are smaller than those of copper windings in a conventional transformer of the same power, and the external winding of a superconducting transformer will be closer to the core. That is why HTS tapes and $\mathrm{Cu}$ leads in individual layers of the windings will be connected with other lines of the leakage flux.

Eddy-current losses are caused by eddy currents induced in the entire volume of the resistive layers of $2 \mathrm{G}$ HTS tapes. Those losses can be limited by lowering the percentage of the resistive layers in the entire superconducting tape. But because of the required mechanical 
strength and electrical parameters of HTS 2G tapes, this percentage is quite high, i.e. 90-95\%. Also, increase of the resistivity of the materials of the substrate layer at a temperature $77 \mathrm{~K}$ causes a decrease of those losses. Because of the resistivity of the substrate layers and the oxide base of the superconductor in $2 \mathrm{G}$ tapes, the eddycurrent losses induced in them are greatly limited.

Self-field losses are caused by the field from the current flowing in the transformer windings. Their value depends on the current density.

The value of the sum of AC losses in HTS windings accounts for only a small percentage of the losses which occur in copper windings of conventional transformers with the same parameters [4].

Losses in iron are constant losses. Their value depends on the core mass and the sheet loss coefficient, but it does not depend on the windings current. Iron losses account for over $60 \%$ of all the losses of a HTS transformer.

Losses in current leads are the sum of Joule losses and the losses of thermal conductivity through the current leads. In order to minimise the access of heat into the cryostat, sectioning of current leads is used. Larger diameter at a higher temperature and smaller diameter at a lower temperature allow to minimise the flow of heat as well as the Joule losses [4].

Cooling of superconducting windings takes place in cryostats in which the required work temperature is obtained and maintained. Power losses in the cryostat are a sum of heat penetrating through cryostat walls by radiation and conduction (through residual gas). These are constant losses, independent of the load.

Losses in the current leads and in cryostat are the largest component of total losses that load the cooling system, and that is why we should try to limit it.

Table I shows the comparison of power losses of 3-phase 63 MVA conventional transformer and the same power rated HTS transformer during nominal load [4].

TABLE I

Power losses of 63 MVA Cu and HTS transformer.

\begin{tabular}{|c|c|c|}
\hline \multirow{2}{*}{ Losses } & \multicolumn{2}{|c|}{ Transformer } \\
\hline & HTS & $\mathrm{Cu}$ \\
\hline constants losses in iron core [kVA] & 70 & 70 \\
\hline \multicolumn{3}{|l|}{ Winding's losses } \\
\hline Joule'a losses & $\mathrm{n} / \mathrm{a}$ & \\
\hline hysteresis and eddy-current losses [kVA] & 8.6 & 250 \\
\hline self-field losses [kVA] & 4.5 & \\
\hline losses in current leads [kVA] & 18 & $\mathrm{n} / \mathrm{a}$ \\
\hline constant cryostat losses [kVA] & 3.4 & $\mathrm{n} / \mathrm{a}$ \\
\hline total losses of transformer $[\mathrm{kVA}]$ & 104.5 & 320 \\
\hline
\end{tabular}

\section{Additional power losses} in superconducting tapes connected in parallel

When rated current of the transformer windings is higher than the critical current of the used superconducting tape, it is necessary to use parallel tapes. In a case of many layers of tapes in a parallel connection, the layer which is the furthest from the air gap is associated with the lowest leakage flux, and the layer which is the closest to the gap is associated with the highest leakage flux. As a result, the currents flow in individual parallel tapes is uneven. It results in the differences in the electromotive forces of the individual tapes, whose effect is the flow of equalization currents which violate the even distribution of the current in the winding [5].

The equalizing current results not only from the not fully used superconducting tapes, e.g. it would be necessary to make the winding using a HTS tape of higher critical current or a parallel package of a larger number of tapes, but also from the occurrence of additional losses in the windings.

The equalization of the equalizing currents can be achieved by transposition of the tapes due to the differences in the diameters of individual turns in the coil. In case of the windings of conventional $\mathrm{Cu}$ transformers, transposition is not problematic. However, to perform classical transposition of $2 \mathrm{G}$ HTS tapes is virtually impossible [5].

On the other hand, the transformers winding made of the package of the parallel tapes is a much cheaper solution than the windings made of e.g. Roebel's cable thanks to the price of HTS $2 \mathrm{G}$ tapes. The number of tapes in a package depends on the critical current of the winding. In order to level the distribution of currents in HTS 2G tapes connected in parallel, it is necessary to develop a technology of connecting the tapes using special connectors which will allow to freely connect tapes between the layers.

Figure 1 shows the idea of transposition of parallel tapes in cylindrical and pancake windings. (a)

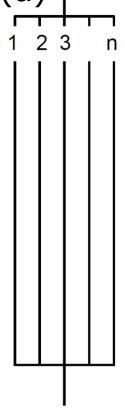

(b)
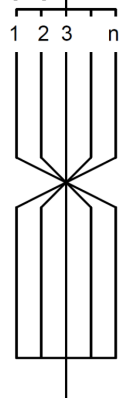

(c)

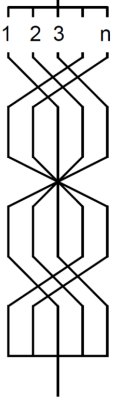

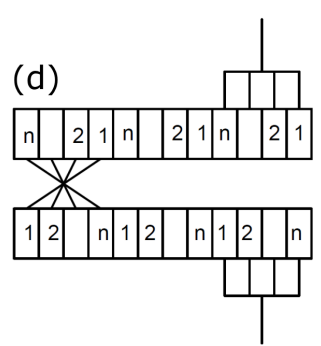

Fig. 1. Idea of transposition of parallel tapes [5]: (a) tapes without transposition, (b) single transposition (at the middle of the winding), (c) fully transposed tapes, (d) transposition in the pancake windings at the transition between adjacent coils.

The additional losses $\Delta P_{a d d}$ are calculated as percentage of losses of the transformer windings $P_{W}$ using the following equations [5]:

$$
\Delta P_{\text {add }}=k P_{W},
$$


- single tape

$k=\left(2 \pi c \sqrt{\frac{n h}{L_{\mathrm{av}}}} \frac{f}{10^{5} \rho}\right)^{4} \frac{m^{2}-0.2}{9}$,

- parallel tapes without transposition (Fig. 2a)

$k=\frac{1}{9}\left(2 \pi c \sqrt{\frac{n h}{L_{\mathrm{av}}}} \frac{f}{10^{5} \rho}\right)^{4}\left(\frac{c^{\prime}}{c}\right)^{2} \frac{4 m^{4}-5 m^{2}+1}{5}$,

- parallel tapes with single transposition (cylindrical and pancake windings, Fig. $2 \mathrm{~b}$ and $2 \mathrm{~d}$ )

$k=\frac{1}{9}\left(2 \pi c \sqrt{\frac{n h}{L_{\mathrm{av}}}} \frac{f}{10^{5} \rho}\right)^{4}\left(\frac{c^{\prime}}{c}\right)^{2} \frac{m^{4}-5 m^{2}+4}{20}$,

- fully transposed tapes (Fig. 2c)

$$
k=\frac{1}{9}\left(2 \pi c \sqrt{\frac{n h}{L_{\mathrm{av}}}} \frac{f}{\rho 10^{5}}\right)^{4}\left(\frac{c^{\prime}}{c}\right)^{2} \frac{m^{4}-20 m^{2}+64}{320}
$$

where $m$ - number of parallel tapes, $n$ - number of turns on layer, $h$ and $c$ - height and thickness of HTS or $\mathrm{Cu}$ tapes, $c^{\prime}$ - thickness of insulated tapes (for HTS tapes $\left.c=c^{\prime}\right), L_{a v}$ - average length of leakage flux lines.

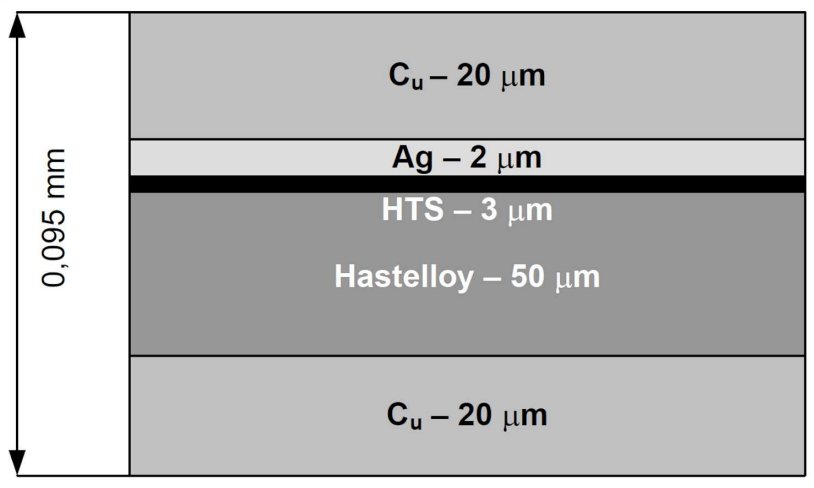

Fig. 2. Cross-section of 2G HTS tapes [6].

The value of $k$ factor depends on the dimensions of the conductor, and thus of the winding thickness, as well as the number of parallel tapes and their resistivity. Figure 2 shows the cross-section of $2 \mathrm{G}$ HTS tape SCS4050/SCS12050. Thickness of that tapes are many fold thinner than the thickness of $\mathrm{Cu}$ conductor. Also to compute the $k$ factor we may consider the resistivity of $\mathrm{Cu}$ layer at the temperature of $77 \mathrm{~K}$, because during superconducting state the current flows through the HTS layer with resistivity equal to $0 \Omega$.

In order to compare the values of $k$ factor of $\mathrm{Cu}$ and HTS transformer the $k$ factors were calculated for the 3-phase $63 \mathrm{MVA} \mathrm{Cu}$ transformer and the same power rated HTS transformer. The parameters of the transformers are given in Table II. The calculated values of $k$ factors are given in Table III.
TABLE II

Parameters of 63 MVA $\mathrm{Cu}$ transformer and the same power rated HTS transformer.

\begin{tabular}{|c|c|c|c|c|}
\hline \multicolumn{5}{|c|}{ Electrical parameters } \\
\hline \multirow{3}{*}{\multicolumn{3}{|c|}{$\begin{array}{l}\text { voltage: primary / secondary }[\mathrm{kV}] \\
\text { vector group of the transformer } \\
\text { rated current of } \mathrm{HV} / \mathrm{LV} \text { winding }[\mathrm{A}]\end{array}$}} & \multirow{3}{*}{\multicolumn{2}{|c|}{$\begin{array}{l}121 / 10.5 \\
\text { Yd11 } \\
300 / 2000\end{array}$}} \\
\hline & & & & \\
\hline & & & & \\
\hline \multicolumn{5}{|c|}{ Copper transformer winding } \\
\hline $\mathrm{HV}$ winding & \multicolumn{4}{|c|}{\begin{tabular}{|l|} 
continuous disc type winding: 24 discs $/$ \\
19 single layers, $\mathrm{Cu}$ tape $-14 \mathrm{~mm} \times 3.3 \mathrm{~mm}$
\end{tabular}} \\
\hline LV winding & \multicolumn{4}{|c|}{$\begin{array}{l}\text { cylindrical: } 1 \text { layer } / 24 \text { parallel tapes fully } \\
\text { transposed, } \mathrm{Cu} \text { tape }-10 \times 2.4 \mathrm{~mm}\end{array}$} \\
\hline \multicolumn{5}{|c|}{ HTS transformer winding } \\
\hline \multirow{4}{*}{\multicolumn{2}{|c|}{$\begin{array}{l}\text { 2G HTS tape } \\
\text { critical current } I_{C}[\mathrm{~A}] \\
\mathrm{HV} \text { winding } \\
\mathrm{LV} \text { winding }\end{array}$}} & \multicolumn{3}{|c|}{ SCS12050-AP } \\
\hline & & \multirow{3}{*}{\multicolumn{3}{|c|}{\begin{tabular}{|c}
300 \\
cylindrical 5 layers / 2 parallel tapes \\
cylindrical 1 layer / 10 parallel tapes
\end{tabular}}} \\
\hline & & & & \\
\hline & & & & \\
\hline & & & $\mathrm{Cu}$ & HTS \\
\hline \multicolumn{3}{|c|}{ HV winding thickness $[\mathrm{mm}]$} & 90 & 1.2 \\
\hline \multicolumn{3}{|c|}{ LV winding thickness [mm] } & 75 & 1.5 \\
\hline
\end{tabular}

TABLE III

Additional loss factor of the 63 MVA $\mathrm{Cu}$ and HTS transformer.

\begin{tabular}{l|c|c|c|c}
\hline \multirow{2}{*}{$k$} & \multicolumn{2}{|c|}{ Cu windings } & \multicolumn{2}{c}{ HTS windings } \\
\cline { 2 - 5 } & HV & LV & HV & LV \\
\hline single tape & 0.3 & - & - & - \\
without transposition & - & 221 & 0.001 & 0.001 \\
single transposition & - & 15 & 0.0006 & 0.0006 \\
fully transposed & - & 0.35 & - & -
\end{tabular}

The values of $k$ factor for $\mathrm{LV}$ winding of $\mathrm{Cu}$ transformer show that the transposition of $\mathrm{Cu}$ tapes is necessary to eliminate the equalizing current and thus to reduction of additional losses. In the real transformer the $\mathrm{LV} \mathrm{Cu}$ winding are fully transposed. It is very important because the total losses of the $\mathrm{Cu}$ windings, including the additional losses, are $250 \mathrm{kVA}$ [4].

In the case of HTS transformer the values of $k$ factor are very small and may be omitted especially since the total losses of the HTS windings are only $13.2 \mathrm{kVA}$ [4]. These values result from very small thickness of HTS windings and low number of parallel tapes due to the value of their critical current.

\section{Cooling system of the transformer winding}

In order to test the applicability of using mechanical cryocoolers for cooling transformer winding, simply model of HTS transformer was designed, whose parameters are shown in Table IV.

The cooling system of the transformer winding will be based on two cryocoolers Cryotel GT (16 W@77 K, $240 \mathrm{~W}$ ) [7]. The system also includes a vacuum cryostat and a thermal shield. Figure 3 shows the CAD model of the cooling system of the transformer windings. 


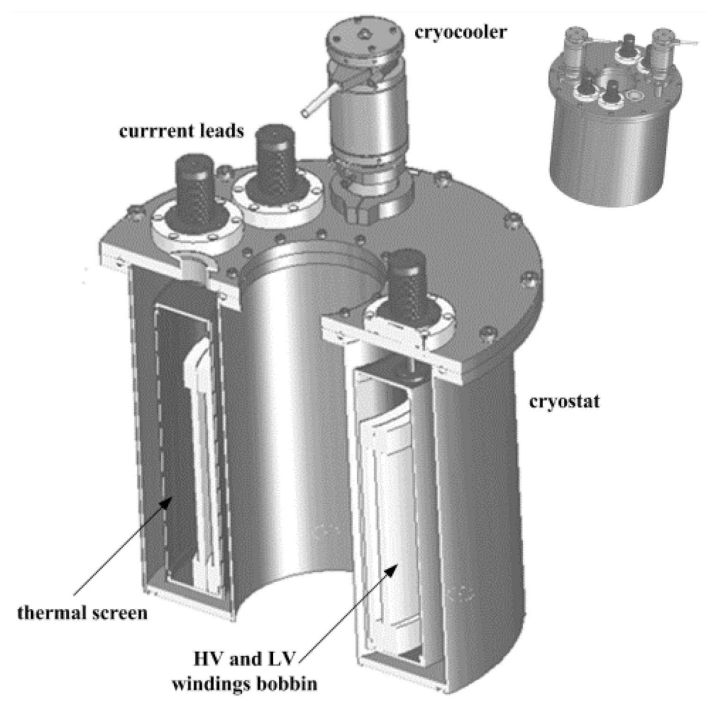

Fig. 3. CAD model of the cooling system of the transformer.

TABLE IV

Parameters of the model of the transformer windings.

\begin{tabular}{l|c|c}
\hline \hline Windings & HV (cylindrical) & LV (pancake) \\
\hline 2G HTS tape & SCS12050-AP & SCS4050-AP \\
width / thickness [mm] & $12 / 0.1$ & $4 / 0.1$ \\
critical current [A] & 240 & 120 \\
$I=70 \% I_{c}[\mathrm{~A}]$ & 168 & 84 \\
\hline \multicolumn{2}{c}{ Electrical parameters } \\
\hline voltage of windings [V] & 400 & 220 \\
rated current of windings [A] & 125 & 228 \\
\hline \multicolumn{2}{c}{ Windings dimensions } \\
\hline turns: $z_{H V} / z_{L V}$ & 62 & 36 \\
layers: $m_{G N} / m_{D N}$ & 3.5 & 4 pancakes \\
turns/layers & 18 & 9 turns/pancake
\end{tabular}

Because of the need to maintain a vacuum of $10^{-6} \mathrm{~Pa}$ for thermal insulation, the cryostat should be made of stainless steel. In addition, polishing the inner walls of the cryostat can significantly reduce the flow of the heat to the cryostat interior through the radiation. The role of the copper thermal screen is to capture thermal loads and guiding them directly to the cooling head of the cryocoolers, Fig. 3. Since the stainless steel cryostat as well as the thermal screen at AC current may be considered as shorted coil, it might prevent the transformer from working properly. Because of this, the copper screen was cut along the axis. After cutting the screen there acts also as a passive radiation screen of the cryostat. The complement of the system are two pairs of copper current leads. The heat generated in the leads will be discharged directly to the thermal screen by conduction through insulating element made of a material of good thermal conductivity. The heat generated in the superconducting windings will be discharged to the thermal screen by a conduction through the current leads and windings bobbins made of a material of good thermal conductivity and placed directly on the screen.
Figure 4 shows the distribution of heat loads in the cooling system of transformer winding, where $Q_{c}$ - heat penetrating through cryostat walls by radiation and conduction (through residual gas), $Q_{c l}$ - heat penetrating through current leads by conduction and the Joule losses, $Q_{w}$ - losses generated in windings (main and additional $\mathrm{AC}$ losses). The total sum of these loads must be less than or equal to the cooling capacity of the used cryocoolers, i.e. $Q_{\text {cryo }}=32 \mathrm{~W}$. In order to check whether a proposed cooling system based on two cryocoolers will be able to obtain and maintain a temperature of $77 \mathrm{~K}$ the thermal balance of the system was performed by analytical calculations. The calculated values of the heat loads entering the cryostat through the cryostat walls and the current leads are included in Table V.

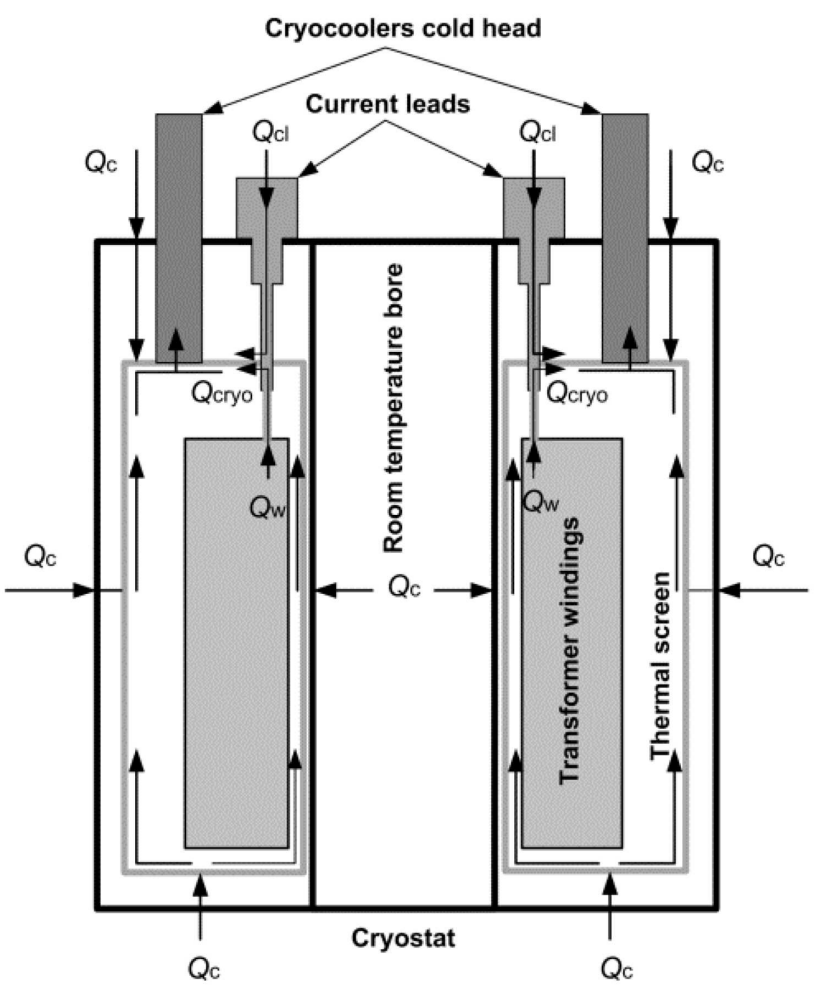

Fig. 4. Distribution of thermal loads in the cooling system of transformer windings.

TABLE V

Thermal balance of the cryostat and current leads.

\begin{tabular}{|c|c|}
\hline \multicolumn{2}{|l|}{ Cryostat } \\
\hline thermal conduction $[\mathrm{W}]$ & 3.2 \\
\hline thermal radiation [W] & 3 \\
\hline \multicolumn{2}{|c|}{ Current leads (2 pair) } \\
\hline thermal conduction $[\mathrm{W}]$ & 21 \\
\hline Joule losses [W] & 1 \\
\hline Total $[\mathrm{W}]$ & 28.2 \\
\hline remaining cooling capacity [W] & 3.8 \\
\hline
\end{tabular}


The thermal balance assumptions were preserved but without considering the heat generated in the windings. Only an experimental research will allow to fully verify the correctness of the cooling system. $75 \%$ of the heat flows into the cryostat through the current leads by a conduction. If after adding the heat generated in the windings the cooling capacity of the refrigerators will be exceeded it may be necessary to optimize the shape and dimensions of the current leads to reduce the heat input.

\section{Conclusions}

The main aim of the paper was to examine the possibility of using small and compact cryocoolers to cooling the model of transformer windings made of parallel $2 \mathrm{G}$ HTS tapes. A vacuum cryostat with a thermal screen as well as the current leads were designed. Calculations and numerical analysis have confirmed the possibility of reaching a temperature of $77 \mathrm{~K}$ in working area of the winding. But only future experimental investigation will allow to fully verify the correctness of the cooling system because we did not consider the heat generated in the winding.

\section{Acknowledgments}

This work is supported by the National Science Centre Poland under grant UMO-2014/15/B/ST8/04682.

\section{References}

[1] G. Wojtasiewicz, T. Janowski, S. Kozak, B. Kondratowicz-Kucewicz, J. Kozak, P. Surdacki, B.A. Glowacki, J. Phys. Conf. Series 43, 821 (2006).

[2] T. Janowski, B.A. Glowacki, G. Wojtasiewicz, S. Kozak, J. Kozak, B. Kondratowicz-Kucewicz, M. Majka, M. Woźniak, IEEE Trans. Appl. Supercond. 21, 1413 (2011).

[3] N. Glasson, M. Staines, N. Allpress, M. Pannu, J. Tanchon, E. Pardo, R. Badcock, R. Buckley, IEEE Trans. Appl. Supercond. 27, 5500205 (2007).

[4] G. Wojtasiewicz, Przegl. Elektrotechn. R90(4), 65 (2014) (in Polish).

[5] E. Jezierski, Transformers - Theoretical Basis, WNT, Warszawa 1965 (in Polish).

[6] Superpower Inc, Configuration of SuperPower ${ }^{\circledR} 2 \mathrm{G}$ HTS Wire.

[7] Sunpower Inc, CryoTel ${ }^{\circledR}$ GT. 